\title{
EXPERIÊNCIAS EM CUIDADO: REFLEXÕES E AÇÕES COM UMA EQUIPE DA ESTRATÉGIA SAÚDE DA FAMÍLIA
}

\author{
Laís Saraiva Torres \\ Universidade Federal do Rio Grande do Norte, Natal, Rio Grande do Norte, Brasil. \\ Viviane Cristina Nascimento da Silva \\ Universidade Federal do Rio Grande do Norte, Natal, Rio Grande do Norte, Brasil. \\ Maria Aparecida Dias \\ Universidade Federal do Rio Grande do Norte, Natal, Rio Grande do Norte, Brasil. \\ Ana Karenina de Melo Arraes Amorim \\ Universidade Federal do Rio Grande do Norte, Natal, Rio Grande do Norte, Brasil. \\ Maria Isabel Brandão de Souza Mendes \\ Universidade Federal do Rio Grande do Norte, Natal, Rio Grande do Norte, Brasil.
}

\begin{abstract}
Resumo
O presente estudo objetivou refletir sobre maneiras de a Educação Física colaborar com práticas corporais e atividades artísticas, na tentativa de superar o modelo tradicional de atenção à saúde e de compreensão do corpo. Trata-se de uma pesquisa baseada na abordagem fenomenológica de Merleau-Ponty, na qual utilizamos o fenômeno situado para refletir sobre as observações, as descrições das entrevistas e os depoimentos. A partir do relato das três oficinas de práticas corporais construídas e vivenciadas pelos profissionais de saúde, foram realizadas as reflexões e discussões dos resultados. Diante das reflexões realizadas pode-se destacar que a Educação Física pode colaborar no desenvolvimento de práticas que despertem a sensibilidade, não tratando o corpo somente como objeto, e na criação dos movimentos e ações humanas, superando o modelo tradicional de atenção à saúde.
\end{abstract}

Palavras-chave: Cuidado. Saúde. Corpo. Educação Física.

\section{Introdução}

No ano de 1988, com a promulgação da nova Constituição Federal, foi criado no Brasil o Sistema Único de Saúde (SUS), tornando o acesso gratuito à saúde como direito de todo cidadão. A institucionalização do SUS foi motivada pela busca da superação do modelo tradicional de atenção à saúde: um modelo pautado na assistência de práticas curativas por meio de intervenções medicalizantes (MENDES; MEDEIROS, 2010).

Diante disso, percebemos que a busca pela superação do modelo tradicional de atenção à saúde está associada à necessidade de ampliação do conceito de saúde, não o considerando apenas como ausência de doença. Trata-se, também, da maneira como o 
corpo humano é compreendido, ou seja, da superação do corpo objeto, do corpo fragmentado, do corpo máquina em seus aspectos de doença.

Nota-se então que, desde sua organização, da maneira de pensar sobre saúde e de refletir sobre o corpo humano, o SUS apresenta princípios e diretrizes que sustentam essas reflexões. Têm-se então como princípios uma atuação profissional que deve garantir a universalidade, equidade e integralidade, que tem relação com o acesso aos serviços, à assistência e a atenção aos usuários (MACHADO, 2007).

A atenção básica em saúde precisa ser estruturada e fortalecida no SUS caracterizando-se por um conjunto de ações que abrange a promoção e a proteção da saúde, a prevenção de agravos, o diagnóstico, o tratamento, a reabilitação e a manutenção da saúde, e que considera os sujeitos em sua singularidade, complexidade, integralidade e inserção sociocultural (OGATA; MACHADO; CATOIA, 2009). Assim, a partir da necessidade de mudança da atenção à saúde, uma proposta dinamizadora do SUS foi o Programa Saúde da Família (PSF) na atenção básica, que, baseada na substituição do modelo tradicional de atenção à saúde, teve como objetivo melhorar a qualidade de vida da população e tornar as ações de saúde próximas da família. Dada a importância que esse programa assumiu no sistema, converteu-se em Estratégia Saúde da Família (ESF).

A Atenção Básica tem a ESF como espaço de reorganização da atenção à saúde, no sentido do desenvolvimento de modos de produzir saúde e modos de gerir os processos de trabalho inovadores que, diferentemente do paradigma biomédico, superem, ampliem e compartilhem a clínica. Implica a construção de processos de saúde nas relações entre equipes, serviços e comunidade de forma conjunta, participativa, democrática, nos quais a gestão do cuidado é convocada a privilegiar a forma com que as relações intersubjetivas se organizam e se manifestam no processo de trabalho, possibilitando o protagonismo e a emancipação dos atores envolvidos na produção de saúde.

Para tanto, entende-se que os diferentes saberes precisam dialogar no campo da produção de saúde. Os saberes populares e científicos têm lugar e relevância na construção de práticas mais coerentes com a realidade de saúde e os recursos existentes nos territórios de vida.

Diante disso, nota-se que a área da Educação Física é recente na discussão sobre a produção de saúde na ESF, sendo escassas as pesquisas sobre iniciativas em conjunto com outros profissionais de saúde. Compreende-se a Educação Física como uma área acadêmica, profissional e pedagógica que se relaciona diretamente com as práticas corporais em saúde no contexto das USFs, constituindo-se mais um saber acadêmico-científico que se pode somar na perspectiva da atenção integral.

De acordo com a perspectiva da integralidade, as ações de saúde devem ser desenvolvidas de forma a superar a dicotomia cura/prevenção, compreendendo o indivíduo como um ser humano integral e complexo que está submetido às mais variadas formas de produção e reprodução social, ou seja, às mais diferentes situações de trabalho e de vida. Tais situações colocam o corpo em contextos que podem ampliar ou constranger as possibilidades de vida, podem promover saúde ou podem enfraquecê-la. Assim, o trabalho com práticas corporais pode ter lugar no âmbito da produção de saúde na atenção básica. E, nesse sentido, a Educação Física tem lugar entre os saberes necessários na construção desse campo.

Pensar a Prática, Goiânia, v. 17, n. 4, out./dez. 2014 
Mendes e Oliveira (2010) identificaram os motivos de não haver atividades que envolvam práticas corporais nas USF, entre esses a falta de espaço e a falta de profissionais capacitados para desenvolvê-las, e quando são realizadas nas USF é por iniciativa de profissionais da equipe da saúde, não necessariamente por professor de Educação Física.

Nesse sentido há um debate presente no campo científico da Educação Física (CARVALHO, 2003, 2006, 2007; FRAGA; WACHS, 2007), necessitando de uma reflexão nos cursos de graduação, acerca da formação e atuação desses profissionais nesses espaços, com um olhar integral e humanista, sem privilegiar somente o biológico.

Para iniciar, então, essa discussão e identificar as possibilidades de a Educação Física dialogar com outros saberes nos cuidados com a saúde na ESF, em sintonia com os princípios do SUS, é importante investigar: como a Educação Física pode colaborar com o desenvolvimento de oficinas de práticas corporais, em conjunto com profissionais de saúde de uma Unidade de Saúde da Família de Cidade Praia em Natal/RN?

\section{As condições de existência - um olhar sobre a localização da Unidade de Saúde Ci- dade Praia}

A cidade de Natal é formada por 36 bairros, divididos em quatro regiões administrativas: norte, sul, leste e oeste ${ }^{1}$. É na região administrativa Norte que se encontra o conjunto habitacional Cidade Praia, que faz parte do bairro Lagoa Azul e teve sua ocupação intensificada com a construção dos quatro conjuntos habitacionais que o integram a partir da década de 1980. Essa foi a "[...] região que mais cresceu na cidade nos últimos vinte anos, no entanto os investimentos em infraestrutura e serviços públicos não acompanharam proporcionalmente tal expansão" (ASSUNÇÃO; ARAÚJO, 2008, p. 52).

Seu nome é justificado por ter surgido em uma área próxima a várias lagoas, entre elas a Lagoa Azul (NATAL, 2010). A ocupação populacional do bairro Lagoa Azul distribui-se nos conjuntos habitacionais, nos loteamentos e nos aglomerados subnormais. Até o ano de 2010, a população residente nesse bairro era de 61.289 habitantes, sendo que, destes, 820 residiam o conjunto habitacional Cidade Praia. Para caracterizar essa localidade em seus aspectos socioeconômicos, segundo Assunção e Araújo (2008), é preciso tomar como referência o bairro em que está inserido.

Acerca de sua infraestrutura e de seus equipamentos urbanos, com dados até 2011, fazem-se presentes no bairro: unidades de ensino (centros municipais de educação infantil, escolas estaduais, escolas municipais e escolas particulares), unidades de segurança pública (bases comunitárias, polícia militar e unidades subordinadas), equipamentos urbanos (feiras e praças), unidades de desporto (campos ou minicampos, complexo desportivo, ginásio e quadras) e as unidades de saúde (um centro de saúde e seis unidades de saúde da família) (NATAL, 2012).

Assim, as unidades de saúde localizadas em Lagoa Azul, entre elas a Unidade de Saúde Cidade Praia, fazem parte do Distrito Norte $\mathrm{I}^{2}$. Segundo informações da Prefeitura

\footnotetext{
1 Essas informações foram retiradas no site da Prefeitura Municipal do Natal. Disponível em: $<$ http://www.natal.rn.gov.br/semurb/paginas/ctd-102.html>. Acesso em: 1o jun. 2013.

${ }^{2}$ Os distritos sanitários da rede municipal de saúde são subdivididos em cinco, que são os distritos Norte I, Norte II, Leste, Oeste e o Distrito Sul.
} 
Municipal de Natal (NATAL, 2009 e 2012), a USF Cidade Praia está sediada na Avenida Três Américas no 811, Cidade Praia, porém, em recente visita, constatou-se que a sede não se encontra mais nesse endereço, no anexo da igreja São José Operário de Cidade Praia. Atualmente, a Unidade de Saúde localiza-se em uma casa alugada, porém, em conversa com um dos profissionais, foi informado que o Governo comprou um terreno para a construção de uma sede definitiva para a USF Cidade Praia.

A equipe multidisciplinar da Unidade de Saúde da Família Cidade Praia constituise de 24 profissionais com diferentes funções: 12 agentes comunitários, quatro técnicos em enfermagem, dois dentistas, duas enfermeiras, um agente administrativo, um auxiliar de serviços gerais, uma diretora e um médico.

\section{Do corpo-objeto ao corpo-sujeito da intervenção}

A perspectiva do modelo tradicional de atenção à saúde leva a uma compreensão de corpo com base no pensamento da Fisiologia clássica, definindo este como um objeto organizado por partes, que se relacionam entre si por meio, unicamente, de relações exteriores e mecânicas, e tem como significação, somente, uma utilidade funcional.

Opondo-se a essa compreensão de corpo-objeto, na perspectiva fenomenológica, de acordo com Nóbrega (2005), o corpo é o próprio Ser. Ele não se apresenta como objeto, é uma unidade, já que não há separação sujeito-objeto em suas ações. Identificamos que o corpo nessa compreensão é condição de existência e está atado ao mundo vivido (MERLEAU-PONTY, 1999).

No sentido de compreensões de corpo no campo da atenção à saúde, Mendes (2007), ao analisar os artigos publicados na Revista Brasileira de Ciências do Esporte $(R B C E)$, mostra que os discursos médicos priorizam considerar o corpo sob uma visão biológica, no qual principalmente os aspectos anátomo-fisiológicos do movimento humano são valorizados.

Na medicina contemporânea, as recentes transformações em direção ao progresso científico e a sofisticação da tecnologia apresentam pontos positivos e negativos. A partir disso, Ayres (2004) destaca como efeitos positivos da medicina contemporânea: os avanços, a aceleração e ampliação do poder de diagnose, a precocidade progressivamente maior de intervenção terapêutica, o aumento da eficiência, a precisão, etc. E com relação aos efeitos negativos o autor citado destaca: autonomia e tirania dos exames complementares, a excessiva segmentação do paciente em órgãos e funções, a desatenção com os aspectos psicossociais do adoecimento.

As práticas de saúde vêm encontrando inúmeros obstáculos para atender de forma efetiva às diversas necessidades de saúde da sociedade. Mesmo com um forte desenvolvimento científico e tecnológico, essas práticas vêm passando por uma importante crise em sua história, pois há "uma progressiva incapacidade das ações de assistência à saúde de se provarem racionais, de se mostrarem sensíveis às necessidades das pessoas e se tornarem cientes de seus próprios limites" (AYRES, 2004, p. 83).

A partir disso, torna-se necessária uma mudança nos aspectos das práticas de saúde, e para a solidificação dessa mudança são necessários esforços coletivos. Uma mudança que ultrapasse os modelos de atendimento tendo como foco somente o corpo humano 
como objeto de intervenções pode ser exemplificada quando Ayres (2004) fala sobre um relato de experiência ao atender uma senhora:

Ao invés disso, prontuário fechado, caneta de volta ao bolso, olhei bem em seus olhos e disse: "hoje eu quero que a senhora fale um pouco de si mesma, da sua vida, das coisas que gosta, ou de que não gosta... enfim, do que estiver com vontade de falar". Sei que uma consulta nunca mais foi igual à outra, e eram de fato "encontros" o que acontecia a cada vinda sua ao serviço (AYRES, 2004, p. 18).

Diferentemente do relato de Ayres, os avanços tecnológicos na saúde tornam o sujeito distante do médico e dele mesmo, de modo que se torna um corpo doente, unicamente. Observa-se, nesse caso, que o atendimento acima não reduz o corpo somente a objeto da intervenção, mas o reconhece como sujeito também.

Desse modo, como o corpo é sujeito-objeto, de natureza sensível, cheio de intenções, significados e sentidos, reduzi-lo a tradições cartesianas, na qual se baseia a fisiologia somente, é negar tudo isso. Ou seja, é não considerar as sensações e as percepções na existência de cada ser, é tratar tudo isso como mera casualidade. Quanto a isso, "MerleauPonty vê a percepção como uma re-criação ou interpretação do mundo. A percepção está diretamente vinculada à motricidade, o corpo é sensível e se revela na motricidade, nos movimentos com sentidos e significados" (NÓBREGA, 2005, p. 69).

De acordo com Merleau-Ponty, "o corpo é, para retomar a expressão de Leibniz, a 'lei eficaz' de suas mudanças. Se ainda se pode falar, na percepção do corpo próprio, de uma interpretação, seria preciso dizer que ele se interpreta a si mesmo" (MERLEAUPONTY, 1999, p. 208). É na compreensão fenomenológica de corpo que as novas práticas em saúde superam o modelo biomédico tradicional.

Trazemos alguns exemplos, tais como: "Rodas de Conversa", "Promovendo Saúde Através da Arte", "Atividade Física com Idosos", "Valorizarte", "Biodança" e "Guarartes", que são experiências consideradas de cuidado, como mostra o estudo de Uchoa (2009), e as quais

[...] são fortemente ancoradas na sensibilidade e criatividade dos profissionais, que atuam como mediadores entre o serviço e a comunidade, estabelecendo pontes, criando condições para a ocorrência de contatos e interações entre campos/contextos culturais e sociais distintos (UCHOA, 2009, p. 309).

Outro exemplo é o estudo de Roble, Moreira e Scagliusi (2012), que teve como objetivo analisar experiências do professor de educação física como profissional de saúde mental, realizando atividade de musicoterapia, exercícios de alongamento e oficinas de culinária, degustação, desempenho, pintura e origami. Essas atividades visavam à formação de vínculo e ao desenvolvimento da escuta, relevantes para a clínica comum e para o cuidado.

3 Essas experiências surgiram a partir de 2002-2003 no município de Natal e estão detalhadas no estudo de Uchoa (2009), que tem como base uma pesquisa realizada no período de 2005 a 2007.

Pensar a Prática, Goiânia, v. 17, n. 4, out./dez. 2014 
Portanto, ao identificarmos que essas experiências ainda são escassas, esta pesquisa objetivou refletir sobre maneiras de a Educação Física colaborar com experiências com práticas corporais e atividades artísticas, na tentativa de superar o modelo tradicional de atenção à saúde e de compreensão do corpo.

\section{Métodos}

Durante o percurso desta pesquisa, baseamo-nos na abordagem fenomenológica de Merleau-Ponty (1999) como referencial metodológico, no sentido de compreender as experiências vividas.

Utilizamos o fenômeno situado como estratégia para a reflexão. O olhar para o fenômeno situado deu-se no observar as vivências dos profissionais de saúde durante as oficinas de práticas corporais e atividades artísticas, identificando que sentidos essas práticas puderam despertar-lhes. Observamos ainda a necessidade e o desejo desses profissionais por essas atividades no dia a dia de trabalho, no que diz respeito aos usos e formas de existir como corpo.

O fenômeno situado como abordagem metodológica foi realizado a partir da observação, da descrição de entrevistas e das falas dos profissionais durante as vivências das oficinas, que foram registradas em diário de campo. Portanto, procuramos compreender os usos do corpo e as expressões deste durante as vivências.

As três oficinas de práticas corporais e atividade artística foram respectivamente: técnicas de respiração, alongamento e relaxamento; técnicas de consciência corporal e elementos da dança e técnicas de cuidado de si e do outro com quadrilha e poesia.

$\mathrm{O}$ número de profissionais que se dispuseram a participar de forma voluntária da pesquisa foram 24, permitindo a realização das entrevistas e dando o consentimento para a utilização de suas falas. Porém, esse número variou entre as oficinas: na primeira participaram 16, na segunda 12 e na terceira, 15 profissionais.

As oficinas não foram escolhidas e nem planejadas de forma aleatória, para sua elaboração foram aplicados questionários sobre as práticas corporais que os profissionais gostariam de vivenciar e quais atividades corporais eles realizavam em seus momentos de lazer. Com as respostas auferidas, referentes aos gostos, às vontades e às experiências desses profissionais; conseguimos respaldo para a construção e realização das três oficinas. As oficinas foram construídas por docentes da Universidade Federal do Rio Grande do Norte em conjunto com os profissionais de saúde.

Nesse sentido, as datas de realização de cada uma das três oficinas também foram escolhidas pelos profissionais e, para todas elas, foi decidido por consenso um dia em que a maioria estivesse disponível para participar e que não prejudicasse o atendimento na USF.

As oficinas foram realizadas no anexo da Igreja São José Operário, em Cidade Praia/Natal/RN. Essa escolha foi feita já que na sede da USF não há um local que possibilite sua realização, apesar de a publicação do Programa Academia da Saúde ter sido feita em 2011 pelo Ministério da Saúde ${ }^{4}$ e esta USF não ser contemplada ainda com esse Programa. Na sala utilizada para o desenvolvimento da oficina encontramos: quadro ne-

4

Pensar a Prática, Goiânia, v. 17, n. 4, out./dez. 2014 
gro, cadeiras, mesas, birô e armário. Assim, foi preciso afastar esses objetos para que os profissionais se distribuíssem nesse espaço. $\mathrm{O}$ tempo de realização das três oficinas foi em torno de uma hora de atividades para cada uma, além do tempo para o debate sobre elas.

\section{Resultados e discussão}

\section{A percepção do corpo e do cuidado nas experiências}

Na primeira oficina, foram desenvolvidas atividades de respiração, alongamento, massagem e relaxamento, com uma proposta de realizar um contato individual e entre o grupo. Assim, houve o contato das mãos com o abdômen no momento da respiração, das mãos com as pernas, coxas, pés e braços no alongamento, e o toque com o outro, na massagem. Foram desenvolvidas atividades com balões de gás, um elemento lúdico que possibilitou a aproximação entre os profissionais.

Por meio da observação, notamos corpos rígidos e eretos no início das atividades e, ao fim, esses estavam relaxados e soltos, em sua maioria. As seguintes falas dos profissionais foram relevantes para o reconhecimento dos corpos:

Revivendo momentos anteriores e percebendo o quanto é bom e importante a técnica de respiração e a concentração consigo.

A prática foi extremamente relevante e importante para o reconhecimento de si e do outro.

Percebi a diferença do toque entre os colegas.

É difícil reconhecer o corpo no dia a dia devido aos problemas, e também é difícil colocar em prática essas atividades de sentir o corpo.

Gosto mais de tocar do que ser tocado.

Sensação de se reconhecer.

Os depoimentos acima permitem refletir sobre a importância da oficina para o despertar da consciência corporal. De acordo com Nóbrega (2005), a percepção do corpo pode ser despertada mediante vivências com técnicas de sensibilização ou por movimentos que despertem a criação e a percepção, opondo-se à racionalização das ações humanas.

Entrelaçado à consciência corporal tem-se o reconhecimento, outro termo bastante citado. Um reconhecimento de que eles não são somente profissionais, mas também sujeitos com um corpo, apenas percebido no dia a dia por meio do cansaço e das dores do

O Programa Academia da Saúde foi criado pela Portaria no 719, de 7 de abril de 2011, e em 2013 foi redefinido pela Portaria no 2.681, de 7 de novembro de 2013. Seu objetivo é "promover práticas corporais e atividade física, promoção da alimentação saudável, educação em saúde, entre outros, além de contribuir para produção do cuidado e de modos de vida saudáveis e sustentáveis da população. Para tanto, o Programa promove a implantação de polos do Academia da Saúde, que são espaços públicos dotados de infraestrutura, equipamentos e profissionais qualificados". Disponível em: $<$ http://portalsaude.saude.gov.br/index.php/o-ministerio/principal/leia-mais-o-ministerio/1028secretaria-svs/vigilancia-de-a-a-z/academia-da-saude-svs/12-academia-da-saude-svs/13816-sobre-oprograma>. Acesso em: 20 nov. 2014.

Pensar a Prática, Goiânia, v. 17, n. 4, out./dez. 2014 
trabalho, implicando posturas tensas com corpos rígidos e disciplinados. Nóbrega (2005) destaca que não há uma análise reflexiva da realidade corporal e que nos tornamos conscientes apenas do caráter global das sensações, daquelas que incomodam o corpo.

Nesse sentido, é um momento importante para se perceber, para fazê-los sentir que estão atados no mundo, que o sujeito é o corpo assim como discorre Foucault (2010), os sujeitos não são substâncias, mas sim uma forma que nem sempre é a mesma, já que as relações com o outro e consigo mesmo são estabelecidas de diferentes formas.

As expressões corporais e as formas como nos colocamos no mundo nas diferentes situações também não se repetem, pois nossas intenções, sensações e significações para essas expressões, que são temporais e históricas, são mutáveis (NÓBREGA, 2005).

Para Merleau-Ponty, "não é ao objeto físico que o corpo pode ser comparado, mas antes à obra de arte" (MERLEAU-PONTY, 1999, p. 208). O corpo está em constante transformação.

$\mathrm{Na}$ segunda oficina foi realizado um momento de alongamento, no intuito de os profissionais se tocarem e perceberem-se; após isso, uma atividade com a proposta de aproximação entre os corpos, no qual se abraçavam, se tocavam, aproximavam-se e distanciavam-se.

As atividades seguintes foram envolvidas pelo ritmo do forró, sendo este um gênero típico da região, no qual os profissionais foram instigados a expressar a si mesmos, ou seja, demonstrar passos do forró que eram conhecidos por cada um deles e/ou criar novos movimentos e, ao fim, divididos em dois grupos, montaram coreografias e apresentaram-nas.

Foi perceptível a mudança na forma de relacionarem-se; a união e integração no momento da coreografia foi o ponto-chave, pois a construção desta ocorreu de forma conjunta e não por meio de uma única pessoa. Tomamos as seguintes falas como fundamentais para essa oficina:

O toque fez com que nos aproximássemos de uma forma que no dia a dia nem nos percebemos.

É difícil tocar o corpo, olhar no olho, de trabalhar com o corpo.

Observamos os profissionais falarem sobre o toque: sua importância, seus modos e a forma de como é tratado. Segundo Montagu (1988), a tatilidade é construída cultural e individualmente (familiar) nas pessoas; por esse viés, entende-se que os profissionais apresentam maneiras diferentes de pensar sobre o contato tátil. Alguns preferem tocar, enquanto outros gostam de ser tocados e, talvez, nem um e nem outro. Assim, a USF é composta e frequentada por diferentes sujeitos, cada um com uma história e Culturas diferentes, trazendo consigo todas essas "marcas" corporais.

Há sociedades que esquecem ou não percebem o toque. E é nesse sentido que essas práticas corporais também são experiências para despertar o sentido do tato, nas relações entre os profissionais de saúde. Essas práticas corporais como experiências despertaram um novo olhar para as práticas em saúde. Para a realização do contato tátil é preciso ter sensibilidade, já que ela varia entre os sujeitos, podendo contribuir nas compreensões dos corpos considerando a subjetividade destes. E não tocá-los como um corpo-objeto, rompendo com o pensamento dualista. 
Merleau-Ponty, em seus estudos, procurou estreitar as relações entre corpo e mundo, concebendo a existência humana como essencialmente corporal e sensitiva na relação com o mundo. Assim, aproxima o que tradicionalmente se separou no pensamento moderno: sujeito e objeto (CARDIM, 2009). Desse modo, o corpo é sujeito e objeto no mundo e com o mundo, não havendo separação ou neutralidade nesta relação sujeito-corpomundo.

Sobre a relação entre corpo, mundo e o outro, Merleau-Ponty destaca que "só sentimos que existimos depois de já ter entrado em contato com os outros, e nossa reflexão é sempre um retorno a nós mesmos que, aliás, deve muito à nossa frequentação do outro" (MERLEAU-PONTY, 2004, p. 48).

Para a última oficina, foram realizadas técnicas de cuidado de si e dos outros, e para esta trouxemos o tecido não tecido (TNT) como um elemento lúdico, o qual foi um elo entre os profissionais, aproximando-os. Serviu também como uma espécie de venda para os olhos, uma atividade para desenvolver o cuidado e o reconhecimento.

A quadrilha veio também como uma experiência inovadora, pois a proposta não foi dançar por dançar, mas, sim, colocar em prática todos aqueles momentos vivenciados, em forma de gestos, de movimento. A integração e a socialização tornaram-nos unidos; o cuidado de si e com o outro se fez presente; a mudança de perceber os corpos também.

Ao perguntarmos "O que sentiram ao serem guiados?" tivemos como respostas:

Confiança.

Seguro, por conhecer o guia.

Já havia participado em outra oportunidade dessa atividade, mas não consegui realizá-la, mas dessa vez consegui.

Outra pergunta foi "O que sentiram ao serem os guias?" e as respostas foram:

Responsável pelo colega.

Útil.

Tive cuidado com o colega.

E, por último, "O que sentiram quando estiveram com os olhos fechados?" e como respostas:

Confiança com o grupo.

Sem referência.

Percebemos um ao outro através do tato; é difícil alguém chegar e tocar no dia a dia.

Aproveitei para abraçar.

Podemos reforçar, diante das falas, a discussão do toque, dessa vez relacionado com o cuidado e com a afetividade. $\mathrm{O}$ afeto muitas vezes tem seu papel esquecido quando se trata de saúde; uma afetividade encontrada na importância do tocar, reaproximando o ser humano da sua animalidade e dos outros (MENDES, 2007).

O corpo também é afetividade, como mostra Merleau-Ponty (1999), e não pode ser reduzido a um mero objeto. Nesse sentido, o filósofo tece críticas ao mundo objetivo, que não considera a afetividade nas relações com o outro.

O mundo objetivo cada vez toca menos diretamente no teclado dos estados afetivos "elementares", mas o valor continua a ser 
uma possibilidade permanente de prazer e de dor. Se não é na experiência do prazer e da dor, da qual não há nada a dizer, o seu jeito define-se por seu poder de representação, e a afetividade não é reconhecida como um modo original de consciência. Se essa concepção fosse justa, todo desfalecimento da sexualidade deveria reconduzir-se ou à perda de certas representações, ou então a um enfraquecimento do prazer.

Reconhecendo a importância da afetividade na relação com os outros, destacamos que o cuidado de si é de certo modo o cuidado dos outros e continuamente tende ao bem dos outros, porém, segundo Foucault (2010), esse cuidado de si em determinado momento e em determinada sociedade foi questionado e, muitas vezes, por haver esse prazer e essa necessidade consigo mesmo, era visto como algo egoísta e de importância pessoal, uma forma de amor a si mesmo, que se distanciava do interesse do outro.

O cuidado de si faz parte da formação humana e de suas relações, mas não necessariamente está presente em todos, como afirma o autor:

[...] o cuidado de si implica também a relação com o outro, uma vez que, para cuidar bem de si, é preciso ouvir as lições de um mestre. Precisa-se de um guia, de um conselheiro, de um amigo, de alguém que lhe diga a verdade. Assim, o problema das relações com os outros está presente ao longo esse desenvolvimento do cuidado de si (Foucault, 2010, p. 271).

Nesse contexto percebemos que o cuidado de si nas oficinas realizadas esteve sempre atrelado ao cuidado com o outro.

Como fechamento das oficinas, propomos aos profissionais a criação de uma poesia, que representasse o significado e os sentidos que aqueles momentos lhes proporcio-

naram. Em conjunto, cada um dando sua contribuição, seja com frases ou palavras, intitularam a poesia da seguinte maneira: "A oportunidade do encontro", que segue abaixo:

Através de cada encontro

Chega a alegria ao coração

Vivenciando cada momento

Unindo útil e agradável

Dividindo momentos difíceis

Celebrando momentos felizes

Respeitando nossos limites

Compartilhando emoções diversas

Revivendo a infância feliz

Tornando o adulto um aprendiz.

Um beijo em tua face deponho, Agradecendo a presente oportunidade

Fortalecendo o espírito do caminhar

Aguardando outro intento

Para celebrar novo encontro 


\section{(Profissionais da USF Cidade Praia).}

A poesia declama os sentimentos despertados nos profissionais a cada encontro. Encontro esse não somente com estudantes de educação física e profissionais de saúde, mas com cada um e entre eles. Um encontro que no dia a dia é despercebido, e esquecedor do ser. Portanto as práticas corporais despertaram essa percepção de seus corpos e do ser que estão em um mundo do qual fazem parte, relacionando-se com a natureza e com os outros, em constante movimento. Entendemos que haverá práticas corporais que despertarão sentidos, reflexões e significados nos seres, enquanto outras não, já que "o homem é simultaneamente sujeito e objeto, ativo e passivo" (CARDIM, 2009, p. 89).

As práticas corporais por si só não são garantia de saúde, deve-se levar em consideração a história e as diversas necessidades corpóreas, ou seja, as práticas corporais podem despertar o conhecimento de si para reconhecer os limites do próprio corpo e do corpo do outro (MENDES, 2007).

\section{Considerações finais}

É um desafio realizar práticas corporais e atividades artísticas na saúde de modo inovador, no sentido de superar o modelo tradicional de atenção à saúde, visto que as práticas curativas por si só esquecem o sensível e inibem os sentidos dos seres humanos.

Respaldando-se na fenomenologia, a realidade biológica do Ser não deve ser negada, porém, atrelada a essa, deve ser considerada a realidade existencial e cultural nas suas experiências e, nesse sentido, despertar seus sentidos, a capacidade de reflexão e de percepção do mundo desse Ser subjetivo (NÓBREGA, 2005).

$\mathrm{Na}$ concepção fenomenológica de corpo a subjetividade é construída na intersubjetividade, ou seja, na relação com o outro, uma vez que não vivemos isolados no mundo (MERLEAU-PONTY, 1999 e 2004).

Essa ampliação de compreender o corpo é também uma superação de pensar sobre práticas corporais e atividades artísticas na saúde. A Educação Física pode colaborar no desenvolvimento dessas práticas que despertam a sensibilidade e a criação de ações humanas. Nesse contexto, o conceito existencial de saúde é relevante para fundamentar essas práticas.

O conceito de saúde numa perspectiva existencial poderá contribuir para que a Educação Física possa ampliar a relação entre saúde e estética a partir de um corpo idealizado e possa atrelar-se a uma estética da vida bela, atenta às necessidades e desejos de cada corpo e de quem convive conosco na sociedade (MENDES, 2007, p. 130).

Acreditamos na formação de profissionais da saúde pautada na compreensão do corpo como sendo biocultural, em que não é somente objeto de intervenção, mas sujeito da existência. A partir disso, acreditamos na superação do modelo tradicional de atenção à saúde e na construção de modos de cuidados com a saúde com mais movimento, cheio de sentidos, intenções, prazeres e desejos para os seres, e não somente exames, tratamentos, medicações. 


\title{
EXPERIENCES IN CARE: REFLECTIONS AND ACTIONS WITH A TEAM IN FAMILY HEALTH STRATEGY
}

\begin{abstract}
The present study aimed to reflect on ways to Physical Education collaborate with bodily practices and artistic activities in an attempt to overcome the traditional model of health care and understanding of the body. It is a research based on the phenomenological approach of MerleauPonty, in which we use the phenomenon situated to reflect on observations, descriptions of interviews and testimonials. After reports of the three workshops built bodily practices experienced by health professionals were conducted reflections and discussions of the results. In front the analyzes can be noted that physical education can collaborate in the development of practices that awaken sensibility, not only treating the body as an object, and in the creation of moviments and humans actions, surpassing the traditional model of health care.
\end{abstract}

Keywords: Care. Health. Corps. Physical Education.

\section{EXPERIENCIAS EN ATENCIÓN: REFLEXIONES Y ACCIONES CON UN EQUIPO EM LA ESTRATEGIA DE SALUD DE LA FAMILIA}

\section{Resumen}

El presente estudio tuvo como objetivo reflexionar sobre las formas de educación física colaborar con las prácticas corporales y actividades artísticas en un intento de superar el modelo tradicional de atención de la salud y la comprensión del cuerpo. Se trata de una investigación basada en el enfoque fenomenológico de Merleau-Ponty, en que utilizamos el fenómeno situado a reflexionar sobre las observaciones, descripciones de entrevistas y testimonios. Después de los informes de los tres talleres de prácticas corporales construídas que experimentadas por profesionales de la salud se llevaron a cabo reflexiones y discusiones de los resultados. Antes de las análisis se puede observar que la educación física puede colaborar en el desarrollo de prácticas que despiertan la sensibilidad, no sólo tratar el cuerpo como un objeto, y en la creación de acciones y movimientos humanos, superando el modelo tradicional de atención de la salud.

Palabras clave: Cuidado. Cuerpo. Salud. Educación Física.

\section{Referências}

ASSUNÇÃO, J. C. F.; ARAÚJO, M. C. C. Pelo direito de ir e vir na cidade: mobilidade urbana e inclusão social em Cidade Praia - Natal/RN. Holos, Natal, ano 24, v. 1, p. 4874, 2008.

AYRES, J. R. C. M. O cuidado, os modos de ser (do) humano e as práticas de saúde. Saúde e Sociedade, v. 13, n. 3, p. 16-29, set./dez. 2004.

AYRES, J. R. C. M. Cuidado e reconstrução das práticas de saúde. Interface: Comunicação, Saúde, Educação, Botucatu, v. 8, n. 14, p. 73-92, set. 2003/fev. 2004. 
BRASIL. Ministério da Saúde. Saúde da família. Disponível em: $<$ http://dab.saude.gov.br/atencaobasica.php $>$. Acesso em: maio 2013.

CARDIM, L. N. Corpo. São Paulo: Globo, 2009.

CARVALHO, Y.M. Formação profissional em políticas públicas de lazer com enfoque na saúde. IN: MARCELLINO, N.C. (Org.). Formação e desenvolvimento de pessoal em lazer e esporte. São Paulo: Papirus, 2003.

. Promoção da saúde, práticas corporais e atenção básica. Revista Brasileira de Saúde da Família, Brasília, v. VII, p. 33-45, 2006.

. Educação Física e Saúde Coletiva. IN: Madel T. Luz. (Org.). Novos saberes e práticas em saúde coletiva: estudo sobre racionalidades médicas e atividades corporais. 3 ed. São Paulo: Hucitec, p. 19-34, 2007.

FOUCAULT, M. Ética, sexualidade, política. 2. ed. Rio de Janeiro: Forense Universitária, 2010.

FRAGA, A. B; WACHS, F. (Org.). Educação física e saúde coletiva: políticas de formação e perspectivas de intervenção. Porto Alegre: UFRGS, 2007.

MACHADO, D. O. A educação física bate à porta: o Programa de Saúde da Família. In: FRAGA, A. B; WACHS, F. (Org.). Educação física e saúde coletiva: políticas de formação e perspectivas de intervenção. Porto Alegre: UFRGS, 2007.

MENDES, M. I. B. S. Mens sana in corpore sano: saberes e práticas educativas sobre corpo e saúde. Porto Alegre: Sulina, 2007.

MENDES, M. I. B. S.; MEDEIROS, L. P. O programa de saúde da família em Natal e as atividades lúdicas. In: MENDES, M. I. B. S.; OLIVEIRA, M. V. F. (Org.). Cenários lúdicos em Unidades de Saúde da Família: reflexões e perspectivas. Natal: IFRN, 2010.

MENDES, M. I. B. S.; MELO, J. P. Notas sobre o corpo, saúde e ludicidade. In: MENDES, M. I. B. S.; OLIVEIRA, M. V. F. (Org.). Cenários lúdicos em Unidades de Saúde da Família: reflexões e perspectivas. Natal: IFRN, 2010.

MENDES, M. I. B. S.; OLIVEIRA, M. V. F. (Org.). Cenários lúdicos em Unidades de Saúde da Família: reflexões e perspectivas. Natal: IFRN, 2010.

MERLEAU-PONTY, M. Fenomenologia da percepção. 2. ed. São Paulo: Martins Fontes, 1999.

MERLEAU-PONTY, M. Conversas - 1948. São Paulo: Martins Fontes, 2004.

MONTAGU, A. Tocar: o significado humano da pele. São Paulo: Summus, 1988.

Pensar a Prática, Goiânia, v. 17, n. 4, out./dez. 2014 
NATAL. Prefeitura Municipal do Natal. Secretaria Municipal de Meio Ambiente e Urbanismo. Natal em detalhes. Natal: Departamento de Informação, Pesquisa e Estatística, 2009.

NATAL. Prefeitura Municipal do Natal. Secretaria Municipal de Meio Ambiente e Urbanismo. Bairros de Natal. 2. ed. Natal: Departamento de Informação, Pesquisa e Estatística, 2010.

NATAL. Prefeitura Municipal do Natal. Secretaria Municipal de Meio Ambiente e Urbanismo. Conheça melhor seu bairro: Lagoa Azul. 2. ed. Natal: Semurb, 2012.

NÓBREGA, T. P. Corporeidade e educação física: do corpo-objeto ao corpo-sujeito. Natal: EDUFRN, 2005.

OGATA, M. N.; MACHADO, M. L. T.; CATOIA, E. A. Saúde da família como estratégia para mudança do modelo de atenção: representações sociais dos usuários. Revista Eletrônica de Enfermagem, v. 11, n. 4, p. 820-829, 2009. Disponível em: $<$ http://www.fen.ufg.br/revista/v11/n4/v11n4a07.htm>. Acesso em: 1o out. 2013.

ROBLE, O. J.; MOREIRA, M. I. B.; SCAGLIUSI, F. B. A educação física na saúde mental: construindo uma formação na perspectiva interdisciplinar. Interface: Comunicação, Saúde, Educação, Botucatu, v. 16, n. 41, p. 567-577, abr./jun. 2012.

UCHÔA, A. C. Experiências inovadoras de cuidado no Programa Saúde da Família (PSF): potencialidade e limites. Interface: Comunicação, Saúde, Educação, Botucatu, v. 13, n. 29, p. 209-311, abr./jun. 2009.

Recebido em: 30/04/2014

Revisado em: 05/09/2014

Aprovado em: 28/11/2014

Endereço para correspondência:

laissaraiva_@hotmail.com

Laís Saraiva Torres

Universidade Federal Do Rio Grande do Norte, Departamento de Educação Física.

Av Salgado Filho s/n

59000-000 - Natal, RN - Brasil

Pensar a Prática, Goiânia, v. 17, n. 4, out./dez. 2014 